\title{
Catalase deficiency in Staphylococcus aureus subsp. anaerobius is associated with natural loss-of-function mutations within the structural gene
}

\author{
Rosario Sanz, ${ }^{1}$ Irma Marín, ${ }^{2}$ Jose A. Ruiz-Santa-Quiteria, ${ }^{1}$ Jose A. Orden, ${ }^{1}$ \\ Dolores Cid, ${ }^{1}$ Rosa M. Diez, ${ }^{1}$ K. Souad Silhadi, ${ }^{3}$ Ricardo Amils ${ }^{2}$ \\ and Ricardo de la Fuente ${ }^{1}$
}

Author for correspondence: Ricardo de la Fuente. Tel: +34 1 3943703. Fax: +34 13943908. e-mail: rifuente@eucmax.sim.ucm.es

1 Departamento Patología Animal I, Facultad de Veterinaria, Universidad Complutense, 28040 Madrid, Spain

2 Centro de Biología Molecular, Universidad Autónoma de Madrid, Cantoblanco, 28049 Madrid, Spain

3 Centre National de Référence de Toxémies à Staphylocoques, EA 1655 Faculté de Médecine, rue Guillaume Paradin, 69372 Lyon cedex 08, France
Degenerate oligonucleotide primers based on internal peptide sequences obtained by HPLC from purified Staphylococcus aureus catalase were used to locate the S. aureus and S. aureus subsp. anaerobius kat regions by PCR. Southern hybridization analysis with a probe derived from a 1.1 kb PCRamplified fragment showed that a single copy of the putative catalase gene was present in the $S$. aureus and $S$. aureus subsp. anaerobius chromosome. The nucleotide sequence of $S$. aureus katA revealed a 1518 bp open reading frame for a protein with $\mathbf{5 0 5}$ amino acids and a predicted molecular mass of 58347 $\mathrm{Da}$, whereas $S$. aureus subsp. anaerobius katB is $1368 \mathrm{nt}$ long and encodes a polypeptide of 455 amino acids with a predicted molecular mass of $52584 \mathrm{Da}$. These catalases are highly homologous to typical monofunctional catalases from prokaryotes. The active-site residues, proximal and distal haem-binding ligands and NADPH-binding residues of the bovine liver catalase-type enzyme were highly conserved in S. aureus KatA. Escherichia coli cells carrying cloned katA had a catalase activity approximately 1000 times that of untransformed $E$. coli, but no detectable increase in catalase activity was observed with $E$. coli carrying cloned katB. Northern blotting showed the presence of a kat-specific transcript in S. aureus subsp. anaerobius, suggesting that the lack of catalase activity in this bacterium is due to a post-transcriptional alteration. Compared to the nucleotide sequence of katA, katB showed a single base-pair deletion and six mis-sense mutations, and these alterations were present in three other S. aureus subsp. anaerobius strains analysed. The deletion, located at $1338 \mathrm{bp}$ from the initiation codon, originates a shift of the nucleotide reading frame and is responsible for the premature translation termination at $1368 \mathrm{bp}$, generating a KatB polypeptide 50 amino acid residues shorter than KatA. Moreover, four of the mis-sense mutations present in kat $B$ lead to nonconservative amino acid replacements, the most significant being that located at residue 317 (Pro in KatA $\rightarrow$ Ser in KatB) because the affected amino acid is involved in determining the proximal haem-binding site. Both the main alterations found in KatB (the deletion and the substitution in residue 317) seem to contribute to the lack of catalase activity in $S$. aureus subsp. anaerobius, as deduced from results obtained with chimeric catalase constructs.

Keywords: catalase, catalase gene, Staphylococcus aureus subsp. anaerobius 


\section{INTRODUCTION}

Staphylococcus aureus subsp. anaerobius is the aetiological agent of abscess disease, a specific lymphadenitis of sheep and goats which affects mainly young animals up to 5-6 months of age (De la Fuente et al., 1985). The disease is characterized by the presence of abscesses in the superficial lymph nodes (De la Fuente \& Suárez, 1985). Experimentally, this bacterium is also pathogenic for ewes by intramammary inoculation, although very high numbers of bacteria $\left(10^{8}\right.$ bacteria $\left.\mathrm{ml}^{-1}\right)$ are required to induce a subclinical or clinical mastitis (De la Fuente et al., 1993). S. aureus subsp. anaerobius is very closely related to S. aureus (De la Fuente et al., 1985, 1987), a major human and animal pathogen. In sheep, $S$. aureus is mainly associated with gangrenous mastitis, dermatitis and pyaemia (Timoney et al., 1988), and ewes are very sensitive to experimental infection with $S$. aureus by the intramammary route: fewer than 100 bacteria are sufficient to produce clinical mastitis (Watson, 1988). Thus, the pathogenic abilities of $S$. aureus and $S$. aureus subsp. anaerobius are very different, and this has been attributed to their distinctive biochemical and physiological characteristics (De la Fuente et al., 1993). The main phenotypic differences between $S$. aureus and $S$. aureus subsp. anaerobius are the weak or negative aerobic growth and the lack of catalase activity in the latter (De la Fuente et al., 1985). In $S$. aureus a correlation between catalase activity and virulence has been observed (Mandell, 1975; Kanafani \& Martin, 1985), suggesting the role of catalase as a defensive mechanism against the oxygen radicals produced by macrophages. S. aureus subsp. anaerobius, however, shares with $S$. aureus the ability to produce extracellular toxins and enzymes (De la Fuente \& Suárez, 1985; De la Fuente et al., 1985), which traditionally have been related to staphylococcal pathogenicity.

Catalase is a haem-containing enzyme involved in dismutation of hydrogen peroxide generated during cellular metabolism to water and molecular oxygen. Most of the catalases characterized can be classified into one of two types based on their enzymological properties: monofunctional or typical catalases, and bifunctional catalase-peroxidases (Loewen, 1992). In many bacteria, both types of catalase are present and each enzyme is encoded by a different gene (e.g. in Escherichia coli, katE and katG code for monofunctional and bifunctional catalases, respectively). Monofunctional catalases have been described as proteins with molecular masses of approximately 220$350 \mathrm{kDa}$ and are normally formed by four identical subunits, each containing one (proto-)haem group (Haas $\&$ Brehm, 1993). Their active centre and NADPHbinding site have also been described in detail (Fita \& Rossmann, 1985a, b). Comparison of the deduced amino acid sequences of these enzymes indicates that typical catalases share regions that are highly conserved among microbial, plant and mammalian enzymes (Switala et al., 1990; Von Ossowski et al., 1993).
In S. aureus, a typical catalase with high levels of enzymic activity and formed by four identical subunits of approximately $60 \mathrm{kDa}$ has been described (Rupprecht \& Schleifer, 1979; Ruiz Santa Quiteria et al., 1992). However, the gene encoding the apoenzyme of staphylococcal catalase has not yet been studied. Previous studies on catalase deficiency of $S$. aureus subsp. anaerobius have shown that this bacterium synthesizes haem (De la Fuente et al., 1987), the prosthetic group of catalase and cytochromes, but that no protein reacting with purified immunoglobulins against $S$. aureus catalase is detected in crude and partially purified cellular extracts (Ruiz Santa Quiteria et al., 1992). These findings suggest that the catalase deficiency of $S$. aureus subsp. anaerobius could be due to mutations in the structural gene of the apoenzyme, or to alterations in the sequences that control its expression. The aim of this work was to establish the molecular basis of the catalase deficiency of $S$. aureus subsp. anaerobius by means of a genetic approach. Cloning, sequencing and characterization of the catalase gene from $S$. aureus was a prerequisite to analysing the corresponding gene from $S$. aureus subsp. anaerobius.

\section{METHODS}

Bacterial strains, plasmids and growth conditions. Bacterial strains, vectors and recombinant plasmids used in this work are described in Table 1. Escherichia coli and S. aureus strains were grown overnight aerobically with agitation at $37^{\circ} \mathrm{C}$ in Luria-Bertani (LB) broth (tryptone, $10 \mathrm{~g} \mathrm{l}^{-1}$; yeast extract, $5 \mathrm{~g}$ $\left.\mathrm{l}^{-1} ; \mathrm{NaCl}, 5 \mathrm{~g} \mathrm{l}^{-1} ; \mathrm{pH} 7 \cdot 2\right)$. S. aureus subsp. anaerobius strains were grown in microaerophilic conditions without agitation. When it was needed, ampicillin was added to a final concentration of $100 \mu \mathrm{g} \mathrm{ml}^{-1}$. For solid media, $15 \mathrm{~g}$ agar $\mathrm{l}^{-1}$ was added.

Purification of $S$. aureus catalase and isolation of internal peptides. $S$. aureus catalase was purified according to the method described by Ruiz Santa Quiteria et al. (1992). Purified catalase was digested with trypsin and the internal peptides obtained were separated by HPLC. Amino acid sequence was determined for two of the internal peptides (CAT 30, GSGAFGTFTV; CAT 21, QDDDNYFEQP); from these sequences the degenerate oligonucleotides cat30 and cat 21 (Table 2) were designed and were used to locate the $S$. aureus and $S$. aureus subsp. anaerobius catalase genes.

Nucleic acid extraction and molecular techniques. Routine DNA manipulations were carried out by standard procedures (Sambrook et al., 1989; Ausubel et al., 1991). Total DNA from $S$. aureus and $S$. aureus subsp. anaerobius strains was extracted by the cetyltrimethylammonium bromide method after pretreatment of bacteria with lysostaphin $\left(1 \mathrm{mg} \mathrm{ml}^{-1}\right)$ for $1 \mathrm{~h}$ at $37^{\circ} \mathrm{C}$ in Tris/EDTA/sucrose (Ausubel et al., 1991). Total RNA was prepared by the method of Kornblum et al. (1988). All restriction endonuclease digestions and ligations were performed as recommended by the suppliers. Plasmids were extracted from E. coli with the plasmid purification kit from Qiagen. When required, DNA restriction fragments or PCR products were separated by agarose gel electrophoresis and purified with the Qiaquick gel extraction kit (Qiagen).

Southern blot analysis. DNA was digested with different restriction enzymes (HindIII, HindIII/SacI, HindIII/SalI) in accordance with the manufacturer's suggestions (New England Biolabs), fractionated on $1 \%$ agarose gels and 
Table 1. Bacterial strains and plasmids used in this study

\begin{tabular}{|c|c|c|}
\hline Strain & Description & Source or reference \\
\hline \multicolumn{3}{|l|}{ S. aureus } \\
\hline ATCC 12600 & Type strain & \\
\hline MN 42 & Clinical isolate from gangrenous mastitis & \\
\hline MN 73 & Clinical isolate from gangrenous mastitis & \\
\hline \multicolumn{3}{|c|}{ S. aureus subsp. anaerobius } \\
\hline MVF 10 & Strain isolated from a lamb affected by abscess disease in 1981 & \\
\hline MVF 89 & Strain isolated from a lamb affected by abscess disease in 1984 & \\
\hline MVF 213 & Strain isolated from a lamb affected by abscess disease in 1988 & \\
\hline MVF 229 & Strain isolated from a lamb affected by abscess disease in 1992 & \\
\hline \multicolumn{3}{|c|}{ Escherichia coli } \\
\hline CC118 & Cloning host strain & Dr de Lorenzo* \\
\hline MOSBlue & Cloning host strain & Amersham \\
\hline \multicolumn{3}{|l|}{ Plasmids } \\
\hline pUC18 & $\mathrm{Amp}^{\mathrm{r}}$ & Yanisch-Perron et al. (1985) \\
\hline pMOSBlue & T-vector for cloning of PCR products & Amersham \\
\hline pKat1 & pMOSBlue, $1 \cdot 1 \mathrm{~kb}$ internal PCR product from kat $A$ gene & This work \\
\hline pKatA & pUC18, $1 \cdot 9-2 \cdot 2 \mathrm{~kb}$ SacI-HindIII fragment with katA gene & This work \\
\hline pKatA1 & pMOSBlue, 1582 bp PCR product with katA gene & This work \\
\hline pKat2 & pMOSBlue, $1 \cdot 1 \mathrm{~kb}$ internal PCR product from katB gene & This work \\
\hline pKatB & pUC18, 5.0-6.0 kb HindIII fragment with katB gene & This work \\
\hline pKatB1 & pMOSBlue, 1582 bp PCR product with katB gene & This work \\
\hline pKatB2 & pMOSBlue, 900 bp internal PCR product from katB gene & This work \\
\hline pKatB3 & pMOSBlue, 1245 bp internal PCR product from katB gene & This work \\
\hline pKatAB & pMOSBlue, katA $5^{\prime}$ end (1033 bp) and katB 3' end (570 bp) & This work \\
\hline pKatBA & pMOSBlue, katB $5^{\prime}$ end (1033 bp) and katA $3^{\prime}$ end (570 bp) & This work \\
\hline
\end{tabular}

* Consejo Superior de Investigaciones Cientificas (CSIC), Madrid, Spain.

transferred to nylon membranes ( $\mathrm{N}+$, Amersham) by the capillary blot technique. DNA probe was radiolabelled with $\left[{ }^{32} \mathrm{P}\right] \mathrm{dCTP}$ by using the Multiprimer DNA labelling system (Amersham Life Science). Prehybridization reactions were carried out at $56{ }^{\circ} \mathrm{C}$ for $1 \mathrm{~h}$ in a solution containing $7 \%(\mathrm{w} / \mathrm{v})$ SDS, $1 \mathrm{mM}$ EDTA and $0.5 \mathrm{M}$ sodium phosphate ( $\mathrm{pH} 7 \cdot 2$ ). Hybridization was performed for $24 \mathrm{~h}$ at $56^{\circ} \mathrm{C}$. The nylon membranes were washed at $45^{\circ} \mathrm{C}$ in $5 \times$ SSC $(1 \times$ SSC is $0 \cdot 15 \mathrm{M} \mathrm{NaCl}$ plus $0 \cdot 015 \mathrm{M}$ sodium citrate) $/ 0 \cdot 1 \%$ SDS for $30 \mathrm{~min}$ and exposed to X-ray films at $-70^{\circ} \mathrm{C}$ for $1-24 \mathrm{~h}$.

Northern blot analysis. Total RNA was separated by electrophoresis on $1 \%$ agarose gels containing $2 \cdot 2 \mathrm{M}$ formaldehyde. Nucleic acids were vacuum-transferred to nylon membranes $(\mathrm{N}+$, Amersham) and cross-linked by UV light. RNA probe was synthesized by in vitro $\mathrm{T}_{3}$ polymerase transcription of pKat1 with digoxigenin-labelled UTP (Boehringer Mannheim) as substrate. Hybridizations were performed at $68{ }^{\circ} \mathrm{C}$ in $5 \times$ SSC plus formamide $50 \%(\mathrm{v} / \mathrm{v})$. Detection was performed with the DIG kit (Boehringer Mannheim) according to the manufacturer's instructions and signals were detected by chemiluminescence. Staphylococcal $16 \mathrm{~S}$ and $23 \mathrm{~S}$ rRNAs were used as size markers.

PCR amplification. Oligonucleotide primers (Table 2) were constructed by Isogen Bioscience. PCR was carried out in a 50 $\mu \mathrm{l}$ volume containing $50 \mathrm{ng}$ genomic DNA with reagents and protocols supplied by the manufacturer (Perkin Elmer). Thermocycler reaction conditions were $1 \mathrm{~min}$ at $94^{\circ} \mathrm{C}, 1 \mathrm{~min}$ at $52{ }^{\circ} \mathrm{C}$ and 1 or $1.5 \mathrm{~min}$ at $72^{\circ} \mathrm{C}$ for 30 cycles. All PCR amplifications included preliminary denaturation at $94^{\circ} \mathrm{C}$ for
$10 \mathrm{~min}$ and a final incubation at $72{ }^{\circ} \mathrm{C}$ for $10 \mathrm{~min}$. Amplified PCR products were analysed by electrophoresis on $1 \%$ agarose gels.

Cloning of catalase. Digested total DNA from $S$. aureus ATCC 12600 or S. aureus subsp. anaerobius MVF 213 was recovered from agarose gels with the Qiaquick gel extraction kit (Qiagen) and ligated with the T4 ligase (Amersham Life Science) into pUC18. Calcium chloride competent E. coli CC118 cells were transformed as described by Sambrook et al. (1989). Transformants were selected on LB agar containing ampicillin $\left(100 \mu \mathrm{g} \mathrm{ml}^{-1}\right)$. Colonies were screened by colony hybridization and by their oxygen formation when they were overlaid with $3 \% \mathrm{H}_{2} \mathrm{O}_{2}$. kat gene fragments amplified by PCR from $S$. aureus or $S$. aureus subsp. anaerobius genomic DNA were cloned in E. coli by using the pMOSBlue T-vector kit (Amersham).

Construction of kat hybrid genes. Recombinant hybrid genes were constructed by the method of gene SOEing or splicing by overlap extension (Higuchi, 1989). Oligonucleotides cat 3 and cat4 (Table 2) are complementary and represent nucleotides from 992 to 1011 of the katA and katB genes. In separate reactions $\left(30\right.$ cycles of denaturation at $94{ }^{\circ} \mathrm{C}$ for $1 \mathrm{~min}$, annealing at $52^{\circ} \mathrm{C}$ for $1 \mathrm{~min}$ and extension at $72{ }^{\circ} \mathrm{C}$ for $1 \mathrm{~min}$ ), oligonucleotides cat 1 and cat 3 and oligonucleotides cat 2 and cat4 were used to amplify, from the kat $A$ and katB genes, PCR products representing sequences from each end of these genes. Samples of the products of each reaction were combined and subjected to a subsequent reaction with oligonucleotides cat 1 and cat 2 to amplify a full-length recombinant product 
Table 2. Oligonucleotide DNA primers utilized in this study

\begin{tabular}{|c|c|c|}
\hline Oligonucleotide & Sequence $\left(5^{\prime}-\mathbf{3}^{\prime}\right)$ & Description \\
\hline cat30 & GGWTCWGGWGCWTTYGGWACWTTYACWGTW & $\begin{array}{l}\text { Degenerate oligonucleotide used for detecting } \\
\text { and cloning kat } A \text { and katB }\end{array}$ \\
\hline cat21 & WGGYTGYTCGAARTARTTRTCRTCRTCYTG & $\begin{array}{l}\text { Degenerate oligonucleotide used for detecting } \\
\text { and cloning kat } A \text { and } k a t B\end{array}$ \\
\hline Cat1 & TATAAATTGTGGAGGGATGAT & $\begin{array}{l}\text { Nucleotides }-22 \text { to }-1 \text { relative to the } 5^{\prime} \text { end of } \\
\text { kat } A \text { used for amplifying the full-length kat } A \\
\text { and kat } B \text { genes and for constructing kat hybrid } \\
\text { genes }\end{array}$ \\
\hline Cat2 & TCATAAACTGCTCAACTACGC & $\begin{array}{l}\text { Nucleotides } 1562 \text { to } 1541 \text { relative to the } 3^{\prime} \text { end of } \\
\text { kat } A \text { used for amplifying the full-length kat } A \\
\text { and katB genes and for constructing kat hybrid } \\
\text { genes }\end{array}$ \\
\hline cat3 & GAATAAACGCCCTTGCAGC & $\begin{array}{l}\text { Nucleotides } 992 \text { to } 1011 \text { of kat } A \text { used for } \\
\text { constructing kat hybrid genes }\end{array}$ \\
\hline cat4 & GCTGCAAGGGCGTTTATTC & Complementary to cat 3 \\
\hline cat5 & TTGTTGCGTTCTAAAATGGAG & $\begin{array}{l}\text { Nucleotides } 641 \text { to } 662 \text { used for amplifying an } \\
\text { internal fragment from katB }\end{array}$ \\
\hline cat6 & TGGGTCAGCTTTGTAACA & $\begin{array}{l}\text { Nucleotides } 1400 \text { to } 1418 \text { used for amplifying an } \\
\text { internal fragment from katB }\end{array}$ \\
\hline
\end{tabular}

representing the $5^{\prime}$ end of $k a t B$ with the $3^{\prime}$ end of $k a t A$ ( $k a t B A$ ) and the $5^{\prime}$ end of katA with the $3^{\prime}$ end of $k a t B$ (kat $\left.A B\right)$. Amplified products were cloned into E. coli by using the pMOSBlue T-vector kit (Amersham) (Fig. 1). Recombinant hybrids thus generated were confirmed by automatic nucleotide sequencing.

DNA sequencing. DNA sequencing was carried out on doublestranded plasmid DNA templates by the dideoxy chaintermination method of Sanger et al. (1977) with a $T_{7}$ sequenase 7-deaza-dGTP DNA sequencing kit (Amersham Life Science). Sequencing was performed with the universal primers or synthetic oligonucleotide primers designed from newly obtained DNA sequences.

Data research and computer analysis. Genetic data were analysed using the University of Wisconsin Genetics Computer Group program library (GCG) (Devereux et al., 1984). CLUSTALX (1.5b) was used for comparison of analysed sequences. Phylogenetic relationships were inferred from a multiple amino acid sequence alignment and a consensus tree was constructed with the program TreeView 1.5.

Preparation of cell lysates. Bacterial lysates were prepared by resuspending cell pellets in $3 \mathrm{ml}$ extraction buffer A $(50 \mathrm{mM}$ Tris/ $\mathrm{HCl}, \mathrm{pH} 8 \cdot 0 ; 0.5 \mathrm{mM}$ EDTA; $50 \mu \mathrm{g}$ sodium azide $\mathrm{ml}^{-1}$; $0 \cdot 25 \mathrm{mg}$ lysozyme $\mathrm{ml}^{-1}$ ). S. aureus and $S$. aureus subsp. anaerobius cells were lysed with $0 \cdot 2 \mathrm{mg}$ lysostaphin $\mathrm{ml}^{-1}$. The suspensions were incubated at $37^{\circ} \mathrm{C}$ for $15 \mathrm{~min}$. Following incubation, $0.3 \mathrm{ml}$ extraction buffer $\mathrm{B}$ was added $(1.5 \mathrm{M} \mathrm{NaCl}$, $0 \cdot 1 \mathrm{M} \mathrm{CaCl}_{2}, 0 \cdot 1 \mathrm{M} \mathrm{MgCl}_{2}, 0.02 \mathrm{mg} \mathrm{DNase} \mathrm{I} \mathrm{ml}{ }^{-1} ; 0.05 \mathrm{mg}$ ovomucoid protease inhibitor $\mathrm{ml}^{-1}$ ). After incubation at room temperature for $5 \mathrm{~min}$, the suspensions were centrifuged at $10000 \mathrm{~g}$ for $1 \mathrm{~h}$. The supernatant was retained and stored in an ice bath or frozen at $-20{ }^{\circ} \mathrm{C}$ until needed. Protein concentration was determined by the Bradford method using bovine serum albumin as the standard.

Polyacrylamide gel electrophoresis and immunoblotting. Protein extracts were separated on $10 \%$ (w/v) polyacrylamide gels under native and denaturing conditions. Denaturing gels were stained with Coomassie blue and nondenaturing gels were stained for enzyme activity as described below. The purified anti-catalase immunoglobulins for Western blot analysis were obtained as described by Ruiz Santa Quiteria et al. (1992).

Determination of enzymic activity. Quantitative determination of catalase activity present in extracts was performed by the colorimetric assay of Sinha (1972). Catalase activity present in extracts was also determined by staining nondenaturing polyacrylamide gels according to the method of Clare et al. (1984) using $5 \mathrm{mM} \mathrm{H}_{2} \mathrm{O}_{2}$.

\section{RESULTS}

\section{Localization and cloning of $S$. aureus and S. aureus subsp. anaerobius catalase genes}

Purified S. aureus catalase was used to design the degenerate oligonucleotides cat21 and cat30 (Table 2) from internal peptides obtained by HPLC. Using these oligonucleotides, a 1100 bp PCR product was amplified from total DNA of $S$. aureus ATCC 12600 and S. aureus subsp. anaerobius MVF 213. To determine whether the amplified fragments were derived from a catalase gene, the $1100 \mathrm{bp}$ PCR products from the two bacteria were cloned into the PCR vector pMOSBlue, generating the plasmids pKat1 and pKat2, respectively (Fig. 2), and sequenced on both strands. The DNA sequences of both fragments had a high degree of homology with other catalases previously described. Thus, the 1100 bp PCR product was used as a probe to locate the $S$. aureus and $S$. aureus subsp. anaerobius catalase genes. To accomplish this, total DNA of both bacteria was digested with different enzymes (HindIII, HindIII/SacI, HindIII/ SalI) and a unique band was detected by hybridization 
(A)

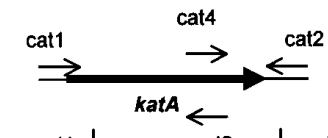

(B)
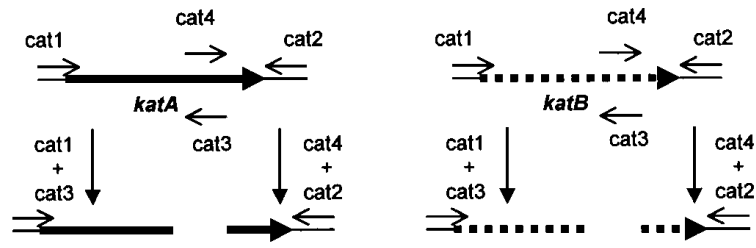

(C)

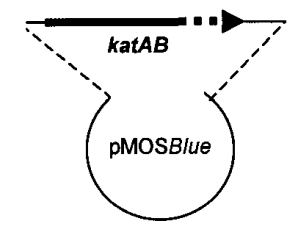

(D)
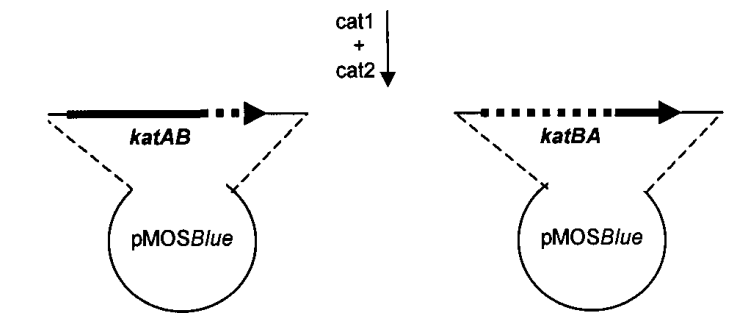

Fig. 1. Strategy for creating kat hybrid genes. Oligonucleotide primers are listed in Table 2. (A) Locations of primers (arrows) in relation to the kat $A$ and $k a t B$ genes. Primers cat 3 and cat 4 are complementary. (B) Separate PCRs amplified two fragments from each gene corresponding to the $5^{\prime}$ and $3^{\prime}$ ends. These fragments have overlapping sequences. (C) The products depicted in (B) were combined and amplified with cat1 and cat2, the outer pair of primers. This step resulted in the constructions shown: kat $A B$, which contains the kat $A 5^{\prime}$ end and the kat $B 3^{\prime}$ end, and katBA, which contains the kat $B 5^{\prime}$ end and the kat $A 3^{\prime}$ end. (D) The constructions shown in (C) were cloned into vector pMOSBlue.

(Fig. 3), which demonstrated that a single copy of the catalase gene was present in both $S$. aureus and $S$. aureus subsp. anaerobius chromosomes. A 1900-2200 bp SacIHindIII fragment from S. aureus total DNA (Fig. 3) was purified and cloned into pUC18, generating the plasmid pKatA (Fig. 2). In the case of $S$. aureus subsp. anaerobius, a 5000-6000 bp HindIII fragment from total DNA (Fig. 3) was purified and cloned into pUC18, generating the plasmid pKatB (Fig. 2). To analyse the $k$ at region of $S$. aureus subsp. anaerobius further, different internal fragments from pKatB were amplified by PCR using oligonucleotide DNA primers deduced from the kat $A$ sequence and cloned into pMOSBlue. The PCR amplification strategy is summarized in Fig. 2.

When E. coli clones were screened for a change in oxygen production upon addition of $3 \% \mathrm{H}_{2} \mathrm{O}_{2}$, clones transformed with katA showed an increase in oxygen formation, but those transformed with $k a t B$ did not show any appreciable increase in oxygen production in comparison with the untransformed control.

\section{Analysis of the catalase nucleotide sequence}

The nucleotide sequence of an internal $1756 \mathrm{bp}$ fragment carried by pKatA was determined on both strands. A $1518 \mathrm{bp}$ single ORF initiating at ATG (base-pair 166) and terminating at TAA (base-pair 1683) was identified within this sequence. The ORF encodes a protein of 505 amino acids with a calculated molecular mass of $58347 \mathrm{Da}$. A -10 region identical to the E. coli consensus sequence was detected upstream of the start codon [TATAAT in S. aureus ATCC 12600 and E. coli (Horwitz \& Loeb, 1990)]. A putative -35 region similar to the corresponding region in E. coli [TTGTAA in $S$. aureus ATCC 12600 and TTGAAG in E. coli (Horwitz \& Loeb, 1990)] was also observed. Finally, a potential ribosome-binding site sequence was found at positions -12 to -8 upstream of the ATG initiation codon (GGAGG). The codon usage was similar to that detected in previously described $S$. aureus genes (Wada et al., 1992). The $65.5 \mathrm{~mol} \% \mathrm{~A}+\mathrm{T}$ content of katA is consistent with the high percentage $\mathrm{A}+\mathrm{T}$ of base-pairs found in other $S$. aureus genes.

In the case of $S$. aureus subsp. anaerobius, sequencing and analysis of a $1747 \mathrm{bp}$ fragment revealed a single ORF of $1368 \mathrm{bp}$ (nucleotides 166-1533). This ORF encodes a protein of 455 amino acids with a predicted molecular mass of $52584 \mathrm{Da}$. Potential -10 and -35 promoter sequences and the putative ribosome-binding site detected in this sequence were identical to those described for S. aureus.

\section{Comparison of amino acid sequences}

The predicted amino acid sequences obtained for KatA and $\mathrm{KatB}$ were compared to other catalase proteins in the GenBank-EMBL/SWISS-PROT databases. The search revealed significant similarities between the analysed catalases and large regions of numerous eukaryotic and prokaryotic catalases. Considering both identical and conservative replacements of amino acids, KatA and KatB showed more than $50 \%$ identity with Bacteroides fragilis catalase KatB, Streptomyces coelicolor catalase CatA, Haemophilus influenzae catalase HktE, Bordetella pertussis catalase KatA, Pseudomonas fluorescens catalase and Neisseria gonorrhoeae catalase (Fig. 4). The degree of similarity was greater in the core of the deduced amino acid sequences than in the $\mathrm{N}$ terminal and C-terminal regions.

Comparison of the deduced amino acid sequence of KatA with the sequence of bovine liver catalase (BLC) revealed that the three residues involved in the active site of the BLC, His-74, Ser-113 and Asn-147 (Fita \& Rossmann, 1985b; Murthy et al., 1981), were conserved in S. aureus KatA at the His-56, Ser-95 and Asn-129 positions. Moreover, the proximal haem site, which comprises Pro-335, Arg-353 and Tyr-357 as ligands in BLC, was localized as Pro-317, Arg-335 and Tyr-339 in KatA. Of the five distal haem-site ligands in BLC, Val73, Arg-111, Thr-114, Phe-152 and Phe-160, the Val-73 residue was replaced by Met-55 while the others were conserved as Arg-93, Thr-95, Phe-134 and Phe-142. In addition, the NADPH-binding site residues of BLC (Fita \& Rossmann, 1985a), Arg-202, His-234 and His-304, seemed to be conserved in KatA as Arg-184, His-216 and His-286, but Asp-212, Tyr-214 and Lys-236 have been replaced by His-194, Phe-196 and Arg-218, respectively.

In the case of the $S$. aureus subsp. anaerobius catalase, all the residues involved in the active site, haem-binding site and NADPH-binding site are identical to those 

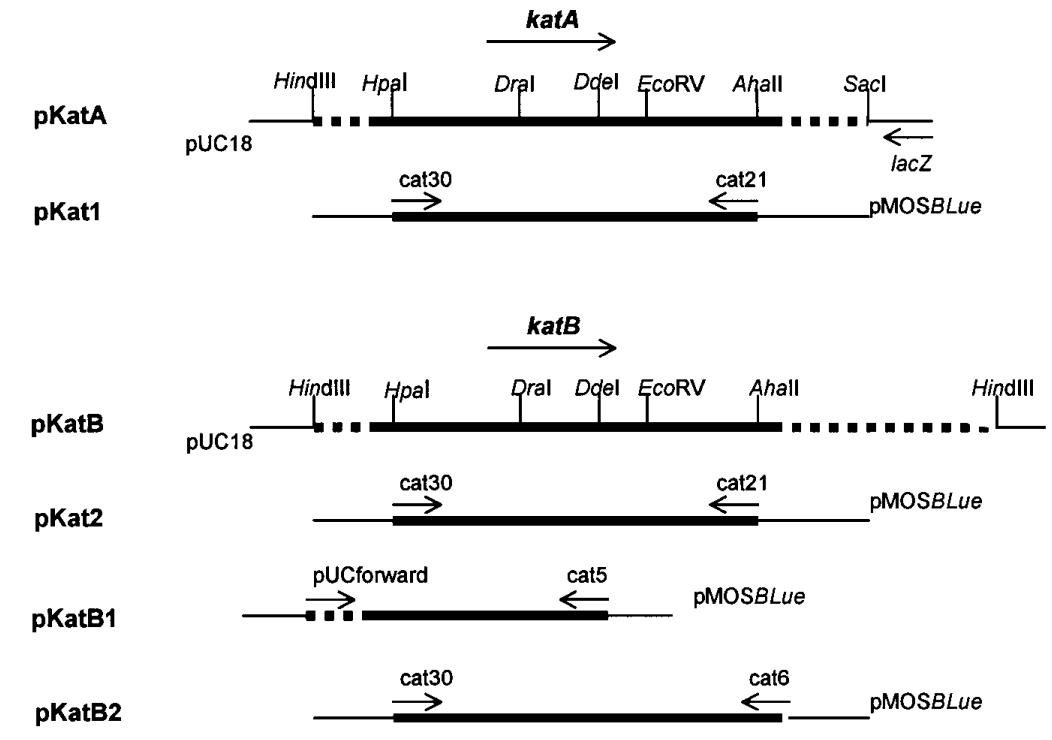

Fig. 2. Restriction map of recombinant plasmids containing the $S$. aureus and $S$. aureus subsp. anaerobius kat genes and subclones derived from these genes. The solid black lines represent cloned kat DNA. The dotted lines represent the flanking regions of the kat genes. described for the $S$. aureus catalase KatA, except the residue Pro-317, involved in the proximal haem-binding site, which is replaced by a Ser residue.

\section{Transcription of katA and katB}

Northern blot assays with a katA-specific RNA probe revealed the presence of a transcript of approximately $1.8 \mathrm{~kb}$ in samples from early-exponential-phase cultures of S. aureus strains ATCC 12600, MN 42 and MN 73 (Fig. 5). Total RNA isolated from exponentially growing cells of $S$. aureus subsp. anaerobius hybridized with the same katA-specific RNA probe, showing the presence of a kat-related transcript larger than that observed in S. aureus (approx. $3.7 \mathrm{~kb}$ ) (Fig. 5). In addition, other smaller positive hybridization signals were detected; these bands are probably degraded katBtranscript products. When samples were collected from stationary-phase cultures of $S$. aureus subsp. anaerobius, no hybridization was detected in the tested strains.

\section{Expression of the recombinant kat $A$ and $k a t B$ genes in $E$. coli}

Protein extracts from E. coli harbouring pKatA showed a level of catalase activity 1000 times higher than the combined activity of E. coli HPI and HPII catalases under the same culture conditions $\left[227 \times 10^{3}\right.$ and $200 \mathrm{U}$ $(\mathrm{mg} \text { protein })^{-1}$, respectively]. However, transformation of E. coli with pKatB did not produce any appreciable increase in catalase activity in relation to the parent $E$. coli strain. In crude extracts from E. coli CC118, two catalase bands were observed corresponding to the previously described E. coli catalases HPI and HPII, whereas crude extracts from $S$. aureus showed a unique band of catalase activity (Fig. 6). Crude extracts of $S$. aureus subsp. anaerobius did not show any band of catalase activity. Crude extracts of E. coli harbouring
pKatA showed one band of catalase activity with similar electrophoretic properties to that of the $S$. aureus purified catalase (Fig. 6). However, crude extracts from E. coli harbouring pKatB showed the same pattern of catalase activity as that observed in the parent E. coli strain.

\section{Analysis of proteins in recombinant $E$. coli}

An additional protein band with a molecular mass of approximately $60 \mathrm{kDa}$ was detected in extracts of $E$. coli CC118(pKatA) in comparison with those of the E. coli CC118 parent strain (Fig. 7a). This additional protein showed an electrophoretic mobility similar to that of purified $S$. aureus catalase. The electrophoretic pattern of E. coli CC118(pKatB) was identical to that of E. coli CC118.

As shown in Fig. 7(b), purified immunoglobulins reacted with a single band of the same molecular mass as that of the electrophoretically pure $S$. aureus catalase in crude extracts of $S$. aureus ATCC 12600 and E. coli CC118(pKatA). However, no band with this electrophoretic mobility was detected in crude extracts either from untransformed E. coli CC118 or from E. coli C118(pKatB). In the extract of E. coli C118(pKatB), a reacting band corresponding to a molecular mass of approximately $20 \mathrm{kDa}$ was detected. This protein was isolated and its $\mathrm{N}$ terminus was sequenced. The sequence obtained indicated that this protein corresponded to lysozyme $\mathrm{C}$, which had reacted non-specifically with purified anti-catalase immunoglobulins.

\section{Comparison of the kat $A$ and $k a t B$ nucleotide sequences}

The nucleotide sequence of $S$. aureus subsp. anaerobius katB showed $98.7 \%$ identity to that of $S$. aureus kat $A$. Comparative analysis of the two sequences revealed the 
(a)

(b)

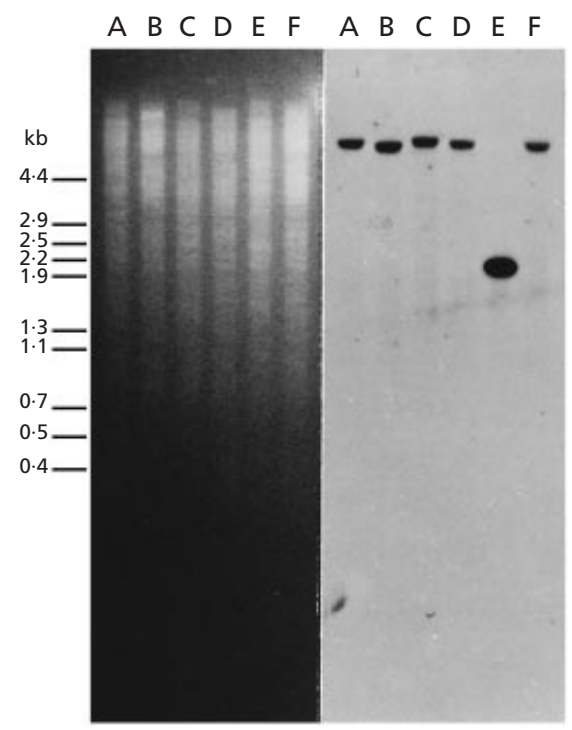

Fig. 3. (a) Agarose gel electrophoresis of digested total DNA from $S$. aureus subsp. anaerobius (lanes $A, B$ and $C$ ) and $S$. aureus (lanes D, E and F). Total DNA of both bacteria was cut with HindIII (lanes A and D), HindIII and Sacl (lanes B and E), or HindIII and Sall (lanes C and F). (b) Southern hybridization analysis of the digested total DNA from $S$. aureus subsp. anaerobius (lanes A, B and C) and S. aureus (lanes D, E and F). The restriction fragments were transferred to nylon membrane and hybridized with the radiolabelled $1100 \mathrm{bp}$ PCR product containing an internal fragment of the katA gene.

presence of several mutations in the $S$. aureus subsp. anaerobius katB gene compared with $S$. aureus kat $A$. Firstly, a single base-pair deletion located at $1338 \mathrm{bp}$ from the initiation codon was found. This deletion would originate a shift of the nucleotide reading frame and, as a consequence, a termination codon (TAA) is present at position 1368. In addition, 14 single base substitutions were found in $k a t B$, eight of which were silent mutations while six were mis-sense. Four of the mis-sense mutations detected in katB lead to a nonconservative replacement of the corresponding amino acid (Arg108Ser, Asp238Gly, Pro317Ser and Asp440Gly) (Fig. 8), while those located at codons 215 and 313 produce a conservative replacement in the KatB amino acid sequence. The most relevant substitution was that located at the first nucleotide of codon 317 (CCA in katA $\rightarrow$ TCA in katB). As result of this mutation, the nonpolar amino acid Pro-317, which is involved in the proximal haem-binding site, was replaced by the polar amino acid Ser-317 (Fig. 8).

To determine whether $k a t B$ mutations were specific for strain MVF 213 or were a more general feature of $S$. aureus subsp. anaerobius, the katB genes of three additional strains isolated from different outbreaks (MVF 10, MVF 89 and MVF 229; Table 1) were amplified by PCR using oligonucleotides cat 1 and cat 2 (Table 2), cloned into E. coli, and sequenced. All of these strains showed the same alterations as described above for strain MVF 213.

\section{Construction and characterization of kat hybrid genes}

The kat $A B$ construction comprises the $5^{\prime}$ end of kat $A$ (of approximately $1033 \mathrm{bp}$ ) and the $3^{\prime}$ end of katB (of approximately $570 \mathrm{bp}$ ). In this construction all of the mutations described above have been repaired except the non-conservative substitution at position 1320 (GAC in $k a t A \rightarrow$ GGC in $k a t B$ ) and the deletion of the nucleotide T-1338. The katBA construction includes the $5^{\prime}$ end of katB (of approximately $1033 \mathrm{bp}$ ) and the 3' end of kat $A$ (of approximately $570 \mathrm{bp}$ ). In katBA the deletion of the T-1338 nucleotide as well as the non-conservative substitution located at the second nucleotide of the codon 440 (GAC in kat $A \rightarrow$ GGC in katB) have been repaired. Recombinant hybrids thus generated were confirmed by automatic nucleotide sequencing. Constructions were cloned into pMOSBlue in E. coli, yielding plasmids $\mathrm{pKat} \mathrm{AB}$ and $\mathrm{pKatBA}$, respectively.

As shown in Fig. 6, E. coli MOSBlue (pKatAB) and E. coli MOSBlue(pKatBA) showed the same pattern of catalase activity as that of the wild-type E. coli strain. In addition, levels of catalase activity showed by E. coli

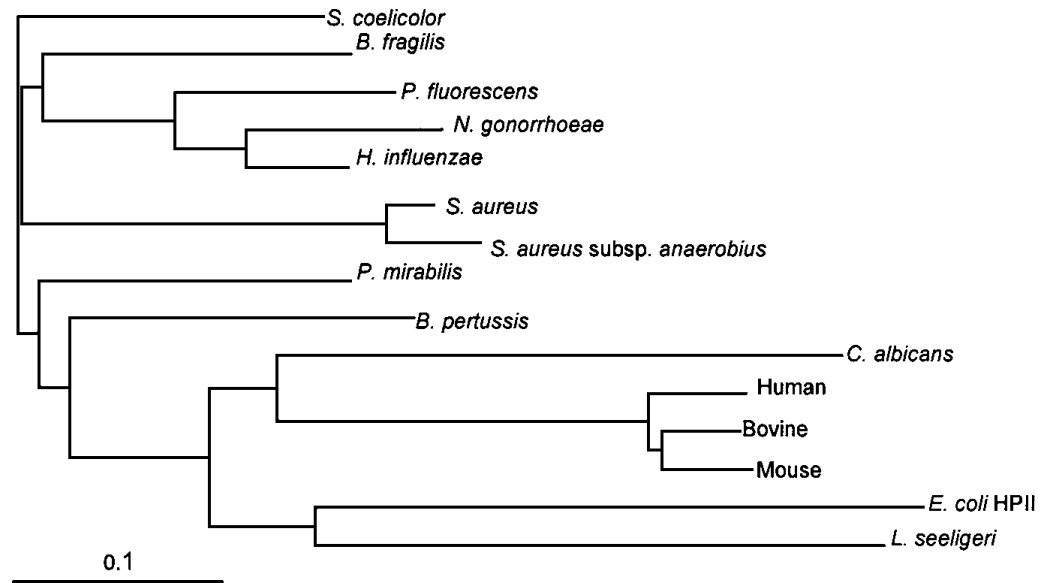

Fig. 4. Phylogenetic relationship of $S$. aureus KatA and $S$. aureus subsp. anaerobius KatB and representative typical catalases. This tree was constructed from a multiple alignment using CLUSTALX (1.5b) and the tree topology was obtained by use of TreeView 1.5 . 


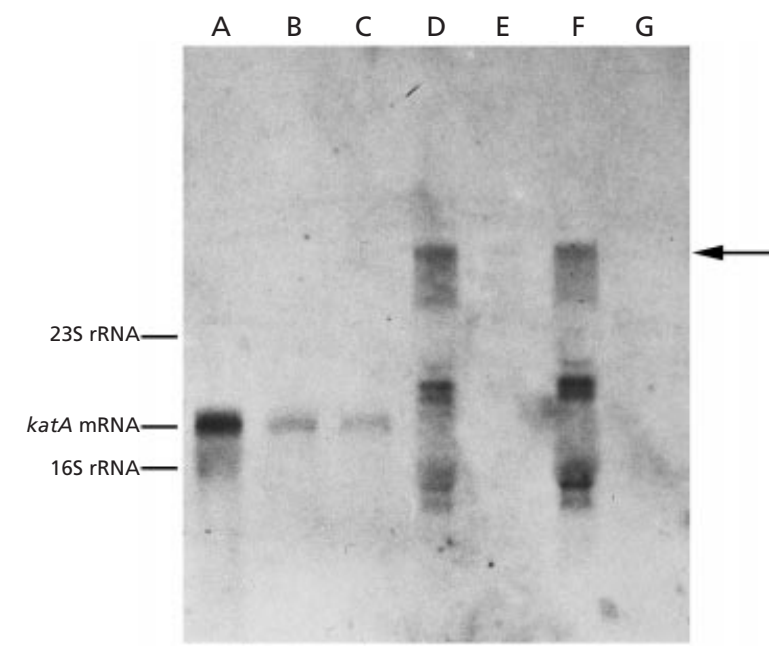

Fig. 5. Northern blot analysis. Whole-cell RNA from different strains of $S$. aureus and $S$. aureus subsp. anaerobius was hybridized with a digoxigenin-labelled RNA probe specific for katA. Lanes A, B, C, D and F correspond to RNAs from earlyexponential-phase cultures and lanes $E$ and $G$ to RNAs from stationary-phase cultures. Lanes: A, S. aureus ATCC 12600; B, S. aureus MN 42; C, S. aureus MN 73; D and E, S. aureus subsp. anaerobius MVF 10; F and G, S. aureus subsp. anaerobius MVF 213. Positions of migration of 16S rRNA (1541 nt) and 23S rRNA (2904 nt) are indicated. The arrow indicates the katB-related transcript.

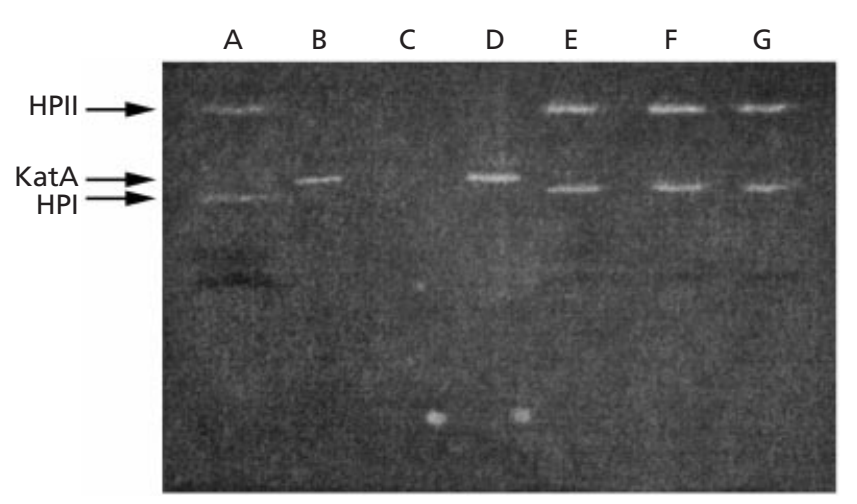

Fig. 6. Detection of catalase activity in crude extracts by the staining method of Clare et al. (1984). Total proteins from extracts of the following bacteria were separated on nondenaturing $10 \%$ polyacrylamide gels: E. coli CC118 (lane A), S. aureus ATCC 12600 (lane B), S. aureus subsp. anaerobius MVF 213 (lane C), E. coli CC118(pKatA) (lane D), E. coli CC118(pKatB) (lane E), E. coli MOSBlue(pKatAB) (lane F) and $E$. coli MOSBlue(pKatBA) (lane G). Crude extracts corresponding to lanes $B$ and $D$ were diluted 1000 -fold due to their high catalase activity. The arrows indicate the position of E. coli HPI and HPII catalases and $S$. aureus KatA catalase.

harbouring kat $A B\left(185 \mathrm{U} \mathrm{mg}^{-1}\right)$ or katBA $\left(190 \mathrm{U} \mathrm{mg}^{-1}\right)$ constructions were similar to that of the E. coli control $\left(200 \mathrm{U} \mathrm{mg}^{-1}\right)$. The protein band pattern of cell lysates from the E. coli parent strain in SDS-polyacrylamide gels was similar to that of the E. coli strains harbouring
pKatAB or pKatBA (Fig. 7a). When cell extracts from $E$. coli harbouring pKatAB or pKatBA were analysed by Western blotting, no protein reacting with the purified immunoglobulins against $S$. aureus catalase was detected (Fig. 7b).

\section{DISCUSSION}

Previous studies have demonstrated that $S$. aureus subsp. anaerobius synthesizes haem (De la Fuente et al., 1987), the prosthetic group of catalase and cytochromes, and that polyclonal antibodies against $S$. aureus catalase do not recognize any protein in cellular extracts from $S$. aureus subsp. anaerobius (Ruiz Santa Quiteria et al., 1992). Based on these results, we planned a genetic approach to clarify the catalase deficiency of this bacterium. As the gene encoding the apoenzyme of catalase had not yet been studied in any of the staphylococcal species, the isolation and sequencing of the $S$. aureus catalase gene was a necessary first step to determine the molecular basis of the deficiency of catalase activity in $S$. aureus subsp. anaerobius.

Expression of katA in E. coli and nucleotide sequence analysis indicated that the cloned DNA encodes the catalase of $S$. aureus. Multiple amino acid sequence alignment showed a strong relationship between KatA and the prokaryotic catalases from Bacteroides fragilis (65\% identity), Streptomyces coelicolor (64\% identity), Proteus mirabilis $(62 \%$ identity) and Haemophilus influenzae (61\% identity). However, the KatA sequence showed less than $50 \%$ amino acid identity with eukaryotic catalases; this is in agreement with data reported by Von Ossowski et al. (1993) and Klotz et al. (1997), who established that animal, plant and fungal catalases in general form a homogeneous group in terms of evolution whereas bacterial catalases appear to have a different phylogenetic origin.

The changes detected in KatA in comparison with BLC in both the proximal haem site (Val-73 in BLC $\rightarrow$ Met-55 in KatA) and the NADPH-binding site (Asp-212 $\rightarrow$ His194, Lys-236 $\rightarrow$ Arg-218 and Tyr-214 $\rightarrow$ Phe-196) have also been described in the Proteus mirabilis catalase (Gouet et al., 1995) and, according to biochemical results and molecular modelling, they do not appear to influence either the specific activity of catalase or the interaction of the enzyme with the NADPH molecule (Gouet et al., 1995).

Northern blotting showed the presence of a kat-specific transcript in samples from exponential-phase cultures of all the $S$. aureus subsp. anaerobius strains tested, although katB is probably transcribed with other gene(s) since the observed transcript in $S$. aureus subsp. anaerobius is larger than that of $S$. aureus controls. The fact that all of the $S$. aureus subsp. anaerobius strains showed a kat mRNA transcript but no catalase activity could be due to a post-transcriptional defect. Western blot assays favour this hypothesis, as none of these strains showed a catalase-specific band with antisera against the purified $S$. aureus catalase. Similar results 


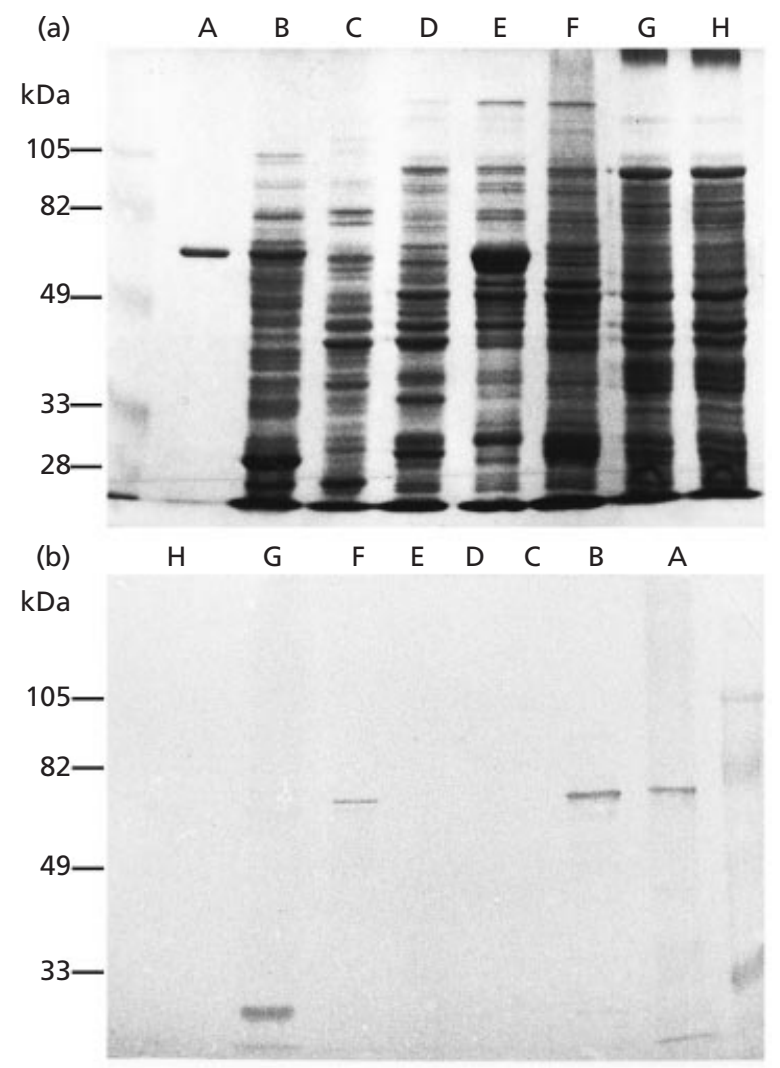

Fig. 7. (a) Denaturing SDS-PAGE gel stained for proteins with Coomassie blue. (b) Detection of catalase in SDS-PAGEseparated crude extracts by immunoblotting. Crude extracts were incubated with purified immunoglobulins against $S$. aureus catalase. Lanes: A, electrophoretically pure catalase from S. aureus ATCC 12600; B, S. aureus ATCC 12600; C, S. aureus subsp. anaerobius MVF 213; D, E. coli CC118; $\mathrm{E}$, E. coli CC118(pKatA); F, E. coli CC118(pKatB); G, E. coli MOSBlue(pKatAB); $\mathrm{H}$, E. coli MOSBlue(pKatBA).

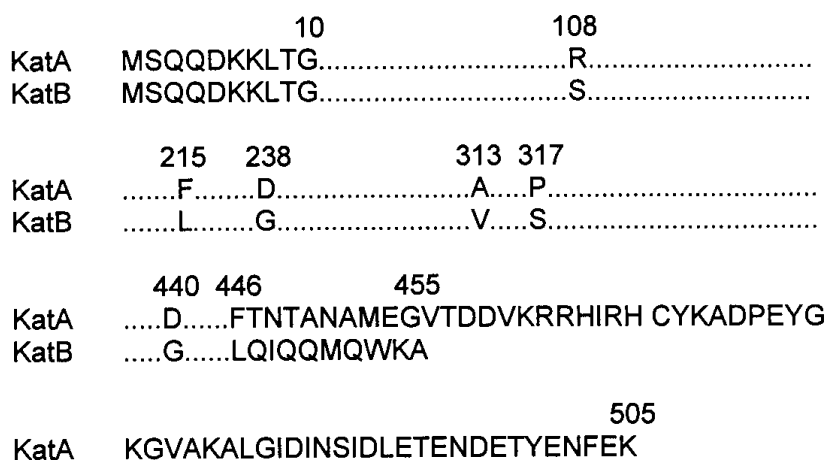

Fig. 8. Differences in the predicted amino acid sequence between KatA and KatB. Numbers indicate the relative amino acid positions.

have been reported in several human-pathogenic isolates of coagulase-negative $S$. aureus, which showed a coa RNA transcript but no detectable coagulase activity (Vandenesch et al., 1994). Whether the lack of a kat- related transcript in samples from stationary-phase cultures of $S$. aureus subsp. anaerobius is related to regulation of catalase gene expression was not investigated; this requires further analysis.

Comparison of the kat $A$ and $k a t B$ nucleotide sequences revealed significant identity $(96.5 \%$ similarity) between the two catalase genes, but there are some mutations in the $S$. aureus subsp. anaerobius catalase gene. Firstly, a single base-pair deletion at position 1338 originates a shift of the nucleotide reading frame and would be responsible for the presence of an early termination codon at $1368 \mathrm{bp}$ from the initiation codon. As a consequence of this deletion, the last 50 amino acids of the C-terminal region of KatB would be absent (Fig. 8). As shown by Rocha \& Smith (1995), The C-terminal region of catalase seems to be essential for enzymic activity. These authors, studying the Bacteroides fragilis catalase gene, found that catalase activity was lost when the last 21 codons of the gene were deleted. Therefore, the loss of the last 50 amino acids from the $\mathrm{C}$ terminus in KatB could account for the catalase deficiency of $S$. aureus subsp. anaerobius. Based upon the threedimensional structure of the Proteus mirabilis catalase (Gouet et al., 1995) and a high degree of similarity between the amino acid sequences of $P$. mirabilis and $S$. aureus subsp. anaerobius catalases, a hypothesis about the role of this deletion in the lack of catalase activity in $S$. aureus subsp. anaerobius could be established. Gouet et al. (1995) determined the structure of the P. mirabilis catalase (484 amino acids) and established that each subunit of this enzyme is composed of four domains. The fourth domain is a bundle of four $\alpha$-helices $(\alpha 10$ to $\alpha 13)$ comprising residues 417 to 484 . Residues in this region are present at the protein surface, exhibit a high temperature factor and could play a role in the protein stability (Fita \& Rossmann, 1985b; Gouet et al., 1995). In addition, these $\alpha$-helices appear to form a pocket lined by several hydrophobic residues where NADPH is bound (Melik-Adamyan et al., 1986), and they contribute to forming the hydrophobic channel leading to the haem group (Murthy et al., 1981). In KatB, as a consequence of the deletion described above, the $\alpha 12$ and $\alpha 13$ helices and part of the $\alpha 11$ helix are not present. The lack of these $\alpha$-helices would produce an alteration of the NADPH peripheral site and could change the entrance of substrate to the active centre. Moreover, the loss of the $\alpha 11, \alpha 12$ and $\alpha 13$ helices in the C-terminal region would sensitize the polypeptide chain to the action of proteases and other degrading enzymes due to the presence of structural changes in the protein surface.

In addition, 14 base substitutions were found in katB, six of which were mis-sense mutations. Four of the missense substitutions in katB would lead to a nonconservative amino acid replacement (Fig. 8), the most significant being that located at position 951 (CCA in $k a t A \rightarrow$ TCA in katB) because the affected amino acid is involved in the proximal haem-binding site. As a result of this mutation, the non-polar amino acid proline is replaced by the polar amino acid serine. Fita \& Rossmann (1985b) described the active centre of BLC 
and proposed that the residue Pro-335 (Pro-317 in KatA) provides a non-polar face which hinders the movement of Tyr-357 (Tyr-339 in KatA). The phenolic hydroxyl group of Tyr-357 interacts with the haem iron and forms hydrogen bonds with Arg-353 (Arg-335 in KatA). Therefore, Pro-335 is involved in the binding of catalase to the haem group and influences the tertiary structure of catalase. The polar serine could thus modify the position of Tyr-339. The Pro $\rightarrow$ Ser replacement could influence binding of catalase to the haem group and could modify the tertiary structure of the protein, thus altering the formation of hydrogen bonds among other amino acids in the polypeptide chain.

With regard to the other non-conservative substitutions described for $k a t B$, it seems that these mutations are not involved in the active site or in the binding of catalase to the haem group and NADPH cofactor. Nevertheless, it cannot be ruled out that some of these amino acid replacements cause a conformational change of the protein such that biological activity of catalase is decreased or nullified.

All of the mutations described in the katB gene isolated from S. aureus subsp. anaerobius MVF 213 were also detected in three other strains of this bacterium isolated from outbreaks of abscess disease which occurred in different Spanish regions from 1981 to 1992. These results suggest that the mutations may be widely present in $S$. aureus subsp. anaerobius strains, and that the strains tested could have a common origin.

Two chimeras (kat $A B$ and katBA) were constructed for establishing whether the two main mutations described above are involved in the lack of catalase activity in $S$. aureus subsp. anaerobius. Both catalase activity and Western blot analysis of the recombinant hybrids were similar to those found in an E. coli wild-type strain. Consequently, each of the two main alterations found in $k a t B$ (the deletion and the substitution in the 317 codon) seems to contribute to the lack of catalase activity in $S$. aureus subsp. anaerobius. Nevertheless, to clarify the individual role of each of the mutations detected in KatB in enzymic activity and in the tertiary structure of the protein, it would be necessary to replace the corresponding residue in $S$. aureus catalase by site-directed mutagenesis and to analyse the biological activity of each variant enzyme.

In conclusion, a 1368 bp gene isolated from S. aureus subsp. anaerobius with high homology to the $S$. aureus kat $A$ gene, described in this report, has been identified and designated as katB. Northern blotting has showed that $k a t B$ is transcribed to mRNA and, therefore, the lack of catalase activity in this bacterium is probably due to a post-transcriptional defect. According to data described in this report and taking into account that transcription and translation occur almost simultaneously in bacteria, a protein similar to but smaller than $S$. aureus catalase is probably synthesized. It is possible that this protein is degraded after synthesis due to the alterations present in the structure and/or in the active site. That could provide an explanation for the lack of reaction of anti-catalase immunoglobulins with crude extracts from $S$. aureus subsp. anaerobius or $E$. coli harbouring the katB gene or the kat hybrid genes.

\section{ACKNOWLEDGEMENTS}

We are very grateful to Gustavo Domínguez for helpful suggestions and to Yvonne Benito for technical assistance.

This work was partially supported by DGICYT (grants PB91-0865 and AGF98-0743).

\section{REFERENCES}

Ausubel, F. M., Brent, R., Kingston, R. E., Moore, D. D., Seidman, J. G., Smith, J. A. \& Struhl, K. (1991). Current Protocols in Molecular Biology. New York: Wiley.

Clare, D. A., Duong, M. N., Darr, D., Archibald, F. \& Fridovich, I. (1984). Effects of molecular oxygen on detection of superoxide radical with nitroblue tetrazolium and on activity stains for catalase. Anal Biochem 140, 532-537.

De la Fuente, R. \& Suarez, G. (1985). Respiratory deficient Staphylococcus aureus as the aetiological agent of 'abscess disease'. Zentbl Vet Med B 32, 397-406.

De la Fuente, R., Suarez, G. \& Schleifer, K. H. (1985). Staphylococcus aureus subsp. anaerobius subsp. nov., the causal agent of abscess disease of sheep. Int J Syst Bacteriol 35, 99-102.

De la Fuente, R., Götz, F. \& Shleifer, K. H. (1987). Comparative biochemical studies on aerobic mutants of Staphylococcus aureus subsp. anaerobius. Syst Appl Microbiol 9, 29-33.

De la Fuente, R., Ruiz Santa Quiteria, J. A., Cid, D., Domingo, M. \& Suarez, G. (1993). Experimental intramammary infection of ewes with Staphylococcus aureus subsp anaerobius. Res Vet Sci 54, 221-226.

Devereux, J., Haeberli, P. \& Smithies, O. (1984). A comprehensive set of sequence analysis programs for the VAX. Nucleic Acids Res 12, 387-395.

Fita, I. \& Rossmann, M. G. (1985a). Tha NADPH binding site on beef liver catalase. Proc Natl Acad Sci USA 82, 1604-1608.

Fita, I. \& Rossmann, M. G. (1985b). The active center of catalase. J Mol Biol 185, 21-37.

Gouet, P., Jouve, H. M. \& Dideberg, O. (1995). Crystal structure of Proteus mirabilis PR catalase with and without bound NADPH. J Mol Biol 249, 933-954.

Haas, A. \& Brehm, K. (1993). Superoxide dismutases and catalases: biochemistry, molecular biology and some biomedical aspects. Genet Eng Biotechnol 13, 243-269.

Higuchi, R. (1989). Using PCR to engineer DNA. In PCR Technology. Principles and Applications for DNA Amplification, pp. 61-70. Edited by H. A. Erlich. New York: Macmillan.

Horwitz, M. S. Z. \& Loeb, L. A. (1990). Structure-function relationship in Escherichia coli promoter DNA. Prog Nucleic Acid Res Mol Biol 38, 137-164.

Kanafani, H. \& Martin, S. E. (1985). Catalase and superoxide dismutase activities in virulent and nonvirulent Staphylococcus aureus isolates. J Clin Microbiol 21, 607-610.

Klotz, M. G., Klassen, G. R. \& Loewen, P. C. (1997). Phylogenetic relationships among prokaryotic and eukaryotic catalases. Mol Biol Evol 14, 951-958.

Kornblum, J. S., Projan, S. J., Moghazeh, S. L. \& Novick, R. P. (1988). A rapid method to quantitate nonlabeled RNA species in bacterial cells. Gene $\mathbf{6 3}, 75-85$. 
Loewen, P. C. (1992). Regulation of bacterial catalase synthesis. In Molecular Biology of Free Radical Scavenging Systems, pp. 96-116. Edited by J. Scandalios. Cold Spring Harbor, NY: Cold Spring Harbor Laboratory.

Mandell, G. L. (1975). Catalase, superoxide dismutase, and virulence of Staphylococcus aureus. In vivo and in vitro studies with emphasis on staphylococcal-leucocyte interaction. J Clin Invest 55, 561-566.

Melik-Adamyan, W. R., Barynin, V. V., Vagin, A. A., Borisov, V. V., Vainshtein, B. K., Fita, I., Murthy, M. R. N. \& Rossmann, M. G. (1986). Comparison of beef liver and Penicillium vitale catalases. J Mol Biol 188, 63-72.

Murthy, M. R. N., Reid, T. J., III, Sicignano, A., Tanaka, N. \& Rossmann, M. G. (1981). Structure of beef liver catalase. J Mol Biol 152, 465-499.

Rocha, E. R. \& Smith, C. J. (1995). Biochemical and genetic analyses of a catalase from the anaerobic bacterium Bacteroides fragilis. $J$ Bacteriol 177, 3111-3119.

Ruiz Santa Quiteria, J. A., Cid, D., Bellahsene, R., Suarez, G. \& De la Fuente, R. (1992). Polyclonal antibodies against Staphylococcus aureus ATCC 12600 catalase do not recognize any protein in cellular extracts from $S$. aureus subsp. anaerobius. FEMS Microbiol Lett 72, 173-176.

Rupprecht, M. \& Schleifer, K. H. (1979). A comparative immunological study of catalases from coagulase-positive staphylococci. Arch Microbiol 120, 53-56.

Sambrook, J., Fritsch, E. F. \& Maniatis, T. (1989). Molecular Cloning: a Laboratory Manual, 2nd edn. Cold Spring Harbor, NY: Cold Spring Harbor Laboratory.
Sanger, F., Nicklen, S. \& Coulson, A. R. (1977). DNA sequencing with chain-terminating inhibitors. Proc Natl Acad Sci USA 74, 5463-5467.

Sinha, A. K. (1972). Colorimetric assay of catalase. Anal Biochem 47, 389-394.

Switala, J., Triggs-Raine, B. L. \& Loewen, P. C. (1990). Homology among bacterial catalase genes. Can J Microbiol 36, 728-731.

Timoney, J. F., Gillespie, J. H., Scott, F. W. \& Baslough, J. E. (1988). The staphylococci. In Hagan and Bruner's Microbiology and Infectious Diseases of Domestic Animals, 8th edn, pp. 171-180. Ithaca \& London: Comstock Publishing.

Vandenesch, F., Lebeau, C., Bes, M., McDevitt, D., Greenland, T., Novick, R. P. \& Etienne, J. (1994). Coagulase deficiency in clinical isolates of Staphylococcus aureus involves both transcriptional and post-transcriptional defects. J Med Microbiol 40, 344-349.

Von Ossowski, I., Hausner, G. \& Loewen, P. C. (1993). Molecular evolutionary analysis based on the amino acid sequence of catalase. J Mol Evol 37, 71-76.

Wada, K., Wada, Y., Ishibashi, F., Gojobori, T. \& Ikemura, T. (1992). Codon usage tabulated from the GenBank genetic sequence data. Nucleic Acids Res 20, 2111-2118.

Watson, D. L. (1988). Vaccination againts experimental staphylococcal mastitis in ewes. Res Vet Sci 45, 16-21.

Yanisch-Perron, C., Vieira, J. \& Messing, J. (1985). Improved M13 phage cloning vectors and host strains: nucleotide sequences of the M13, mp18 and pUC19 vectors. Gene 33, 103-119.

Received 11 October 1999; accepted 5 November 1999. 